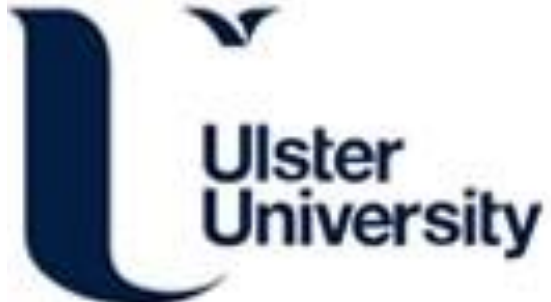

\section{Platinum Integrated Graphene for Methanol Fuel Cells}

Shang, N., Papakonstantinou, P., Wang, P., \& Silva, SRP. (2010). Platinum Integrated Graphene for Methanol Fuel Cells. Journal Of Physical Chemistry C, 114(35), 15837-15841. https://doi.org/10.1021/jp105470s

Link to publication record in Ulster University Research Portal

\section{Published in:}

Journal Of Physical Chemistry C

Publication Status:

Published (in print/issue): 01/08/2010

DOI:

10.1021/jp105470s

\section{Document Version}

Publisher's PDF, also known as Version of record

\section{General rights}

Copyright for the publications made accessible via Ulster University's Research Portal is retained by the author(s) and / or other copyright owners and it is a condition of accessing these publications that users recognise and abide by the legal requirements associated with these rights.

\section{Take down policy}

The Research Portal is Ulster University's institutional repository that provides access to Ulster's research outputs. Every effort has been made to ensure that content in the Research Portal does not infringe any person's rights, or applicable UK laws. If you discover content in the Research Portal that you believe breaches copyright or violates any law, please contact pure-support@ulster.ac.uk. 


\title{
Platinum Integrated Graphene for Methanol Fuel Cells
}

\author{
Naigui Shang* \\ Advanced Technology Institute (ATI), University of Surrey, Guildford, Surrey, GU2 7XH, U.K., and \\ Nanotechnology and Integrated Bio-Engineering Centre (NIBEC), University of Ulster, \\ Newtownabbey BT37 OQB, U.K.
}

\section{Pagona Papakonstantinou}

NIBEC, University of Ulster, Shore Road, Newtownabbey BT37 OQB, U.K.

\author{
Peng Wang \\ UK SuperSTEM, Daresbury Laboratory, Cheshire WA4 4AD, U.K.
}

\section{S. Ravi. P. Silva}

ATI, University of Surrey, Guildford, Surrey GU2 7XH, U.K.

Received: June 14, 2010; Revised Manuscript Received: August 11, 2010

\begin{abstract}
Uniform and porous graphene nanoflake films (GNFs) have been investigated as a support for catalytic Pt nanoclusters in direct methanol electro-oxidation. Pt nanoclusters of varying thickness are deposited on GNFs using magnetron sputtering, and their effects on the electrocatalytic activity for oxidizing methanol are systemically studied. GNF supported Pt nanoclusters with ultralow catalyst loading exhibit high performance for methanol electrocatalytic oxidation with a large mass-specific peak current density and a ratio of forward to backward peak currents up to 1.4. These characteristics compare favorably to the majority of $\mathrm{Pt}-\mathrm{C}$ based electrodes, except for those of carbon nanotubes with Pt decoration on both the inner and the outer wall surfaces. The results obtained are ascribed to a highly coupled network made of high-density $2-4 \mathrm{~nm} \mathrm{Pt}$ monolayer nanoclusters on both the basal and edge planes of each nanoflakes of graphene. GNFs are a promising support material for developing next-generation advanced Pt based fuel cells and their relevant electrodes in the field of energy.
\end{abstract}

\section{Introduction}

Graphene has generated much interest and excitement in the science and technology community since its discovery, and identification of its unique physical structure has given rise to quantum phenomena being observed even at room temperature in 2004. ${ }^{1}$ Besides the reported superior electrical conductivity and outstanding mechanical properties, as a monolayer thick material, graphene has a high surface-to-volume ratio and a theoretical mass-specific surface area up to $2630-2965 \mathrm{~m}^{2} \mathrm{~g}^{-1}$. This surface-to-mass ratio is much larger than that of other carbon materials such as carbon nanotubes (CNTs) and carbon black, etc. ${ }^{2,3}$ Thus, graphene has a unique advantage as a supporting platform for use of catalytic metallic materials to electro-oxidize methanol compared to other nanomaterials such as carbon black, ${ }^{4}$ carbon nanotube/nanofiber, ${ }^{5} \mathrm{CN}_{x}$ nanotube, ${ }^{6}$ nanoporous gold leaf, etc. ${ }^{7-9}$ Recently, we have reported the high-rate growth of graphene nanoflake films (GNFs) directly on $\mathrm{Si}^{10}{ }^{10} \mathrm{GNFs}$ are composed of a large quantity of vertically stacked few-layer graphene nanoflakes with highly crystalline quality and form a porous interlaced homogeneous network. The vertical orientation of graphene nanoflakes leads to the exposure of graphene edges on the surface. Combining this with their outstanding electronic conductivity, GNF offers an excellent electrochemical test bed to study surface interactions and

* To whom correspondence should be addressed. E-mail: ngshang@ hotmail.com. Phone: +44-1483-689866. Fax: +44-1483689404. dynamics. In this work, GNFs are chosen as a novel support type for mediating the metal catalytic electro-oxidation of methanol. Different thicknesses of Pt nanoclusters are supported on the surface of graphene nanoflakes, and their properties are studied with the aim of optimizing various factors such as low precious metal loading, high current density, and fast mass and electron transport rate such that no compromise is made of the electrochemical activity and efficiency monitoring.

\section{Experimental Section}

GNFs with $1.2 \mu \mathrm{m}$ thickness were grown on heavily doped Si wafers by microwave plasma chemical vapor deposition (CVD). The detailed growth conditions can be found in our previous paper. ${ }^{9} \mathrm{Pt}$ nanoclusters with a range of thicknesses between 2.1 and $85.0 \mathrm{~nm}$ were deposited on the surface of GNFs by magnetron sputtering. The chamber had a base pressure of less than $4 \times 10^{-6}$ Torr. The sputter process was carried out in Ar using a dc power at a pressure of about $5 \times 10^{-3}$ Torr. The thickness of Pt nanoclusters was controlled by tuning the sputtering time and was calibrated using depositions onto a flat Si substrate under identical conditions. The surface morphology, microstructure, and chemical composition of Pt decorated GNFs were studied by a scanning electron microscope (SEM) and a $100 \mathrm{kV}$ scanning transmission electron microscope (STEM) with a spherical aberration corrector. Electro-oxidation of methanol was studied in a three-electrode cell using an Autolab electrochemical workstation. A saturated $\mathrm{Ag} / \mathrm{AgCl}$ solution, a Pt wire, 

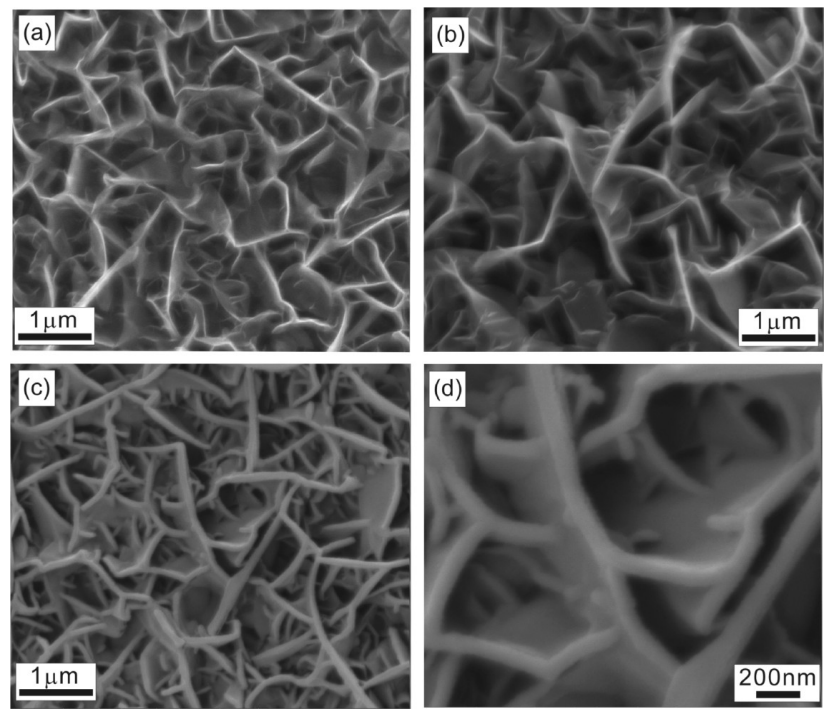

Figure 1. (a) SEM images of the pristine GNFs. (b, c) SEM images of GNFs coated by Pt nanoclusters with different thicknesses of 2.1 and $85.0 \mathrm{~nm}$, respectively. (d) Enlarged SEM images of (c).

and the Pt nanocluster decorated GNF were used as the reference, counter, and working electrodes, respectively. A 10 $\mathrm{mL}$ cylinder cell was specially designed for use of thin film based working electrodes. The electrochemical cell with a projected working area of $0.196 \mathrm{~cm}^{2}$ was sealed with a $5 \mathrm{~mm}$ diameter O-ring and exposed to the electrolyte. $\mathrm{A} \mathrm{Cu}$ foil was tightly fixed with electrically conducting paste on the back of Si substrate entirely for good electrical contact. Before any measurements, all solutions were bubbled by flowing pure $\mathrm{N}_{2}$ for 5-10 min and maintained under the $\mathrm{N}_{2}$ ambient throughout the measurements. All cyclic voltammetric (CV) measurements were performed for at least five cycles, until a reliable and repeatable response was achieved. All data presented here were collected from the fifth cycle. The scan rate in all experiments is $50 \mathrm{mV} / \mathrm{s}$.

\section{Results and Discussion}

Typical SEM images of the pristine GNFs and the $\mathrm{Pt}$ nanocluster decorated GNFs are shown in Figure 1. It is observed that both the pristine and Pt coated GNFs show a highly porous and wavy structure. GNFs with $2.1 \mathrm{~nm}$ thick Pt nanoclusters are composed of interlaced vertical, thin graphene nanoflakes, which maintain the rippled morphology of pristine GNFs. With increasing Pt nanocluster thickness, the film ripples thicken in all dimensions, manifesting a layer of uniform $\mathrm{Pt}$ nanoclusters coated on both the basal and edge planes of each graphene nanoflake as shown in Figure 1d. Energy dispersive $\mathrm{X}$-ray spectroscopy (EDS) microprobe illustrates that the sample is composed of $\mathrm{C}$ and $\mathrm{Pt}$ elements with the characteristic energy peaks at 2.1 and $9.4 \mathrm{keV}$, respectively, as shown in the inset of Figure $2 \mathrm{a}$. Elements present include $\mathrm{O}$ and $\mathrm{Si}$, which originate from surface adsorbates and the substrate, respectively. Figure 2a,b shows low-magnification STEM images of the $2.1 \mathrm{~nm}$ thick Pt nanoclusters on GNFs. It is clear that the graphene nanoflakes bend, overlap, and form a petal-like scaffolding structure in a highly rippled 3D form. As-deposited Pt nanoparticles homogeneously cover the whole surface of each graphene nanoflake. The Pt nanoclusters appear to coalesce into a highly interlinked network on both the edge and basal planes of graphene nanoflakes as shown in the high-magnification STEM images of Figure 2c. The Pt nanoclusters are on average $2-4 \mathrm{~nm}$ in size and are more than $4.0 \times 10^{12} \mathrm{~cm}^{-2}$ in areal density. The graphene nanoflakes show a distinct lattice fringe with a 0.336 $\mathrm{nm}$ spacing of (0002) plane, confirming they are highly graphitized and of high quality. Figure $2 \mathrm{~d}$ shows a high angle annular dark field (HAADF) image of $2.1 \mathrm{~nm}$ thick $\mathrm{Pt}$ nanoclusters on GNFs. The Pt nanoclusters with a suitable orientation show one- or two-dimensional lattice fringes which give a $0.224 \mathrm{~nm}$ spacing associated with the Pt (111) plane, revealing that the Pt nanoclusters are highly crystalline and faceted. When a slightly defocused electron beam was used to observe the nanoclusters, clear lattice fringes of underlying graphenes can be observed from each of the dark void regions among the Pt nanoclusters. This is a strong evidence that the deposited Pt nanoclusters are a monolayer uniform coverage, such that this $\mathrm{Pt}-\mathrm{C}$ electrode has an ultralow Pt loading less than $4.5 \mu \mathrm{g} \mathrm{cm}^{-2}$ and a good interconnected dispersion for lowcost and highly efficient fuel cell applications.

The success of Pt nanocluster decorated graphene nanoflakes was further evidenced by a series of electrochemical $\mathrm{CV}$ profiles in $0.5 \mathrm{M} \mathrm{H}_{2} \mathrm{SO}_{4}$ shown in Figure 3a. Different from the pristine GNFs without any redox peaks, the Pt nanocluster decorated GNFs present a distinct $\mathrm{Pt}$ oxide reduction peak, whose potential increases from 0.404 to $0.429 \mathrm{~V}$ with increasing of Pt nanocluster thickness from 2.1 to $85.0 \mathrm{~nm}$. This potential difference reveals the presence of a strong interaction between $\mathrm{Pt}$ nanoclusters and graphene nanoflakes, similar to that of other $\mathrm{Pt}-\mathrm{C}$ composite electrodes. Based on this, one of the key parameters which impact on the current intensity of fuel cells, the real surface area of Pt nanoclusters that participate in the electrochemical reaction, can be determined from the charge of the $\mathrm{Pt}$

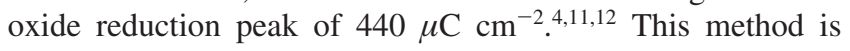
considered to be better than that based on the hydrogen absorption/desorption peaks due to the stronger intensity and well-defined profile without a double-layer-charge induced background. Figure $3 \mathrm{~b}$ shows the mass-specific real surface area of Pt nanoclusters as a function of the thickness from 2.1 to $85.0 \mathrm{~nm}$. Note that the actual more precise mass-specific surface area could be larger than that presented here because the calculation of the Pt mass is based on a continuous and dense film without any voids. The mass-specific surface area for the $2.1 \mathrm{~nm}$ thick Pt nanocluster coated GNFs is largest, up to 89.9 $\mathrm{m}^{2} \mathrm{~g}^{-1}$, which is larger than that of Pt decorated CNT, ${ }^{13-15}$ carbon black, or graphene oxide. ${ }^{16}$ This means that the $2.1 \mathrm{~nm}$ thick Pt nanocluster coated GNFs have low Pt loading levels and high interconnected dispersion degree of catalysts, which are both fundamentally important for highly efficient, low-cost fuel cells. With the thickness of Pt nanoclusters from 2.1 to $85.0 \mathrm{~nm}$, the mass-specific real surface substantially decreases from 89.9 to $12.6 \mathrm{~m}^{2} \mathrm{~g}^{-1}$, close to that of pure Pt materials, ${ }^{15}$ as expected based on a surface to volume argument for nanoscale device structures. The scaling is far from linear, with a 40 time reduction in nanocluster size giving rise to a surfaceto-volume increase of about a factor of 7.

Figure 4a shows typical CV profiles of GNFs with different thicknesses of $\mathrm{Pt}$ nanoclusters for the methanol electro-oxidation in $0.5 \mathrm{M} \mathrm{H}_{2} \mathrm{SO}_{4}+1.0 \mathrm{M} \mathrm{CH}_{3} \mathrm{OH}$ using a scan rate of $50 \mathrm{mV} / \mathrm{s}$ in a potential range of $0-1.0 \mathrm{~V}$. All $\mathrm{CV}$ profiles consist of two strong anodic peaks: a forward peak and a backward peak, which are well-known to originate from the electro-oxidation of methanol and the intermediate carbonaceous species, respectively. The $2.1 \mathrm{~nm}$ thick Pt decorated GNF demonstrates the highest forward and backward mass-specific peak-current densities of 11.77 and $10.76 \mathrm{~mA} \mathrm{~cm}^{-2} \mathrm{~g}^{-1}$, respectively. With the increase of the thickness of Pt nanoclusters, mass-specific current 

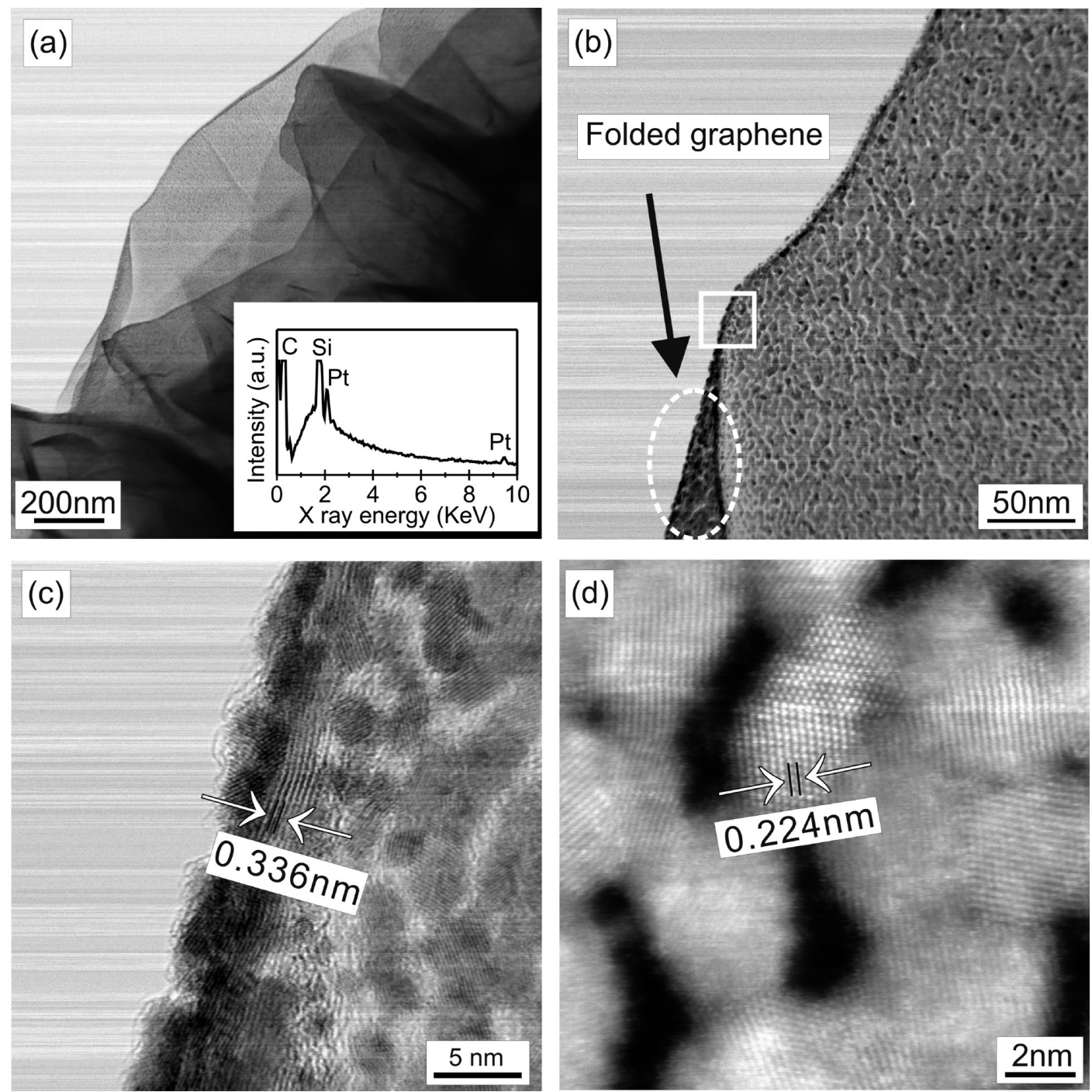

Figure 2. ( $\mathrm{a}, \mathrm{b})$ Low-magnification STEM images of $2.1 \mathrm{~nm}$ thick Pt nanoclusters coated GNFs. Inset is the corresponding EDS spectrum taken in SEM. High-resolution STEM (c, enlarged image of the marked square area of (b)) and HAADF (d) images of $2.1 \mathrm{~nm}$ Pt nanoclusters on GNFs, revealing 2-4 nm monolayer Pt nanoclusters well intercoupled on both basal and edge planes of high-quality GNFs.

density of both anodic peaks greatly decreases. Figure $4 \mathrm{~b}$ shows the mass-specific current density of methanol oxidation peak and the ratio $\left(I_{\mathrm{f}} / I_{\mathrm{b}}\right)$ of forward and backward peak currents as a function of the thickness of Pt nanocluster decoration. The massspecific peak current density significantly decreases from 11.77 to $0.48 \mathrm{~mA} \mathrm{~cm}^{-2} \mathrm{~g}^{-1}$ at the thickness range of Pt nanoclusters of $2.1-10.6 \mathrm{~nm}$ and then almost keeps constant at the thickness range up to $85.0 \mathrm{~nm}$. However, the ratio of forward to backward peak currents first increases from 1.09 at $2.1 \mathrm{~nm}$ Pt nanocluster coated GNFs to $1.39-1.41$ at $5.3-10.6 \mathrm{~nm} \mathrm{Pt}$ nanocluster coated GNFs and then decreases to 0.71 at the $85.0 \mathrm{~nm} \mathrm{Pt}$ nanocluster coated GNFs. The $I_{\mathrm{f}} / I_{\mathrm{b}}$ ratio of $1.40 \pm 0.01$ presented here is close to that of the $\mathrm{Pt} / \mathrm{C}$ prepared by a supercritical fluid method ${ }^{17}$ and Pt nanocluster coated 10-20 layer graphene stacked nanosheets prepared by chemical reduction of exfoliated graphite oxide. ${ }^{8}$ The reported value here of 1.40 is larger than that of many carbon supported $\mathrm{Pt}$ based electrodes such as commercial $\mathrm{Pt}-\mathrm{C}$ catalysts, single wall/ multiwall CNT supported Pt nanoparticles, ${ }^{18-20}$ and costly Pt decorated nanoporous gold leafs, ${ }^{7}$ but less than that of template synthesized CNTs with Pt decorated inner and outer surfaces. ${ }^{15}$ The ratio is a useful fingerprint to evaluate the electrode efficiency, i.e., the tolerance of catalysts to poisoning, and has been found to basically increase with the applied anodic potential limit. ${ }^{13,17}$ The larger the ratio, the more methane molecules are oxidized and the less incompletely oxidized $(\mathrm{C}-\mathrm{O})$ species accumulate on the surface of electrodes used, meaning that the electrode performs well. Another critical parameter for methanol fuel cells is the mass-specific peak current density of electrodes. The maximum mass-specific peak current density for $\mathrm{Pt}$ nanocluster decorated GNFs is $11.77 \mathrm{~mA} \mathrm{~cm}^{-2} \mathrm{~g}^{-1}$, larger than that (about $1 \mathrm{~mA} \mathrm{~cm}^{-2} \mathrm{~g}^{-1}$, calculated by the electrochemical active area and the mass activity) of Pt decorated nanoporous gold leaf. ${ }^{7}$ For other electrodes, this value is not available due to the unknown mass of Pt used. With the increase of thickness of Pt nanoclusters, both the $I_{\mathrm{f}} / I_{\mathrm{b}}$ ratio and mass-specific current density significantly decrease. This trend is consistent with previously reported results, where support materials with large surface areas and highly dispersive coupled, small sized catalysts always possess a high activity for the electro-oxidation of methane..$^{5}$ Increased larger size and lower dispersion of catalysts are believed to contribute to the smaller mass-specific current density and peak current ratio. Combining with the larger massspecific current density and peak current ratio, $2.1-5.3 \mathrm{~nm}$ thick Pt nanocluster decorated GNFs demonstrate the best performance with a mass-specific current density of $11.77-4.12 \mathrm{~mA}$ $\mathrm{cm}^{-2} \mathrm{~g}^{-1}$ and a peak current ratio of $1.09-1.39$. If we make a rough calculation of the Pt loading based on a continuous dense 

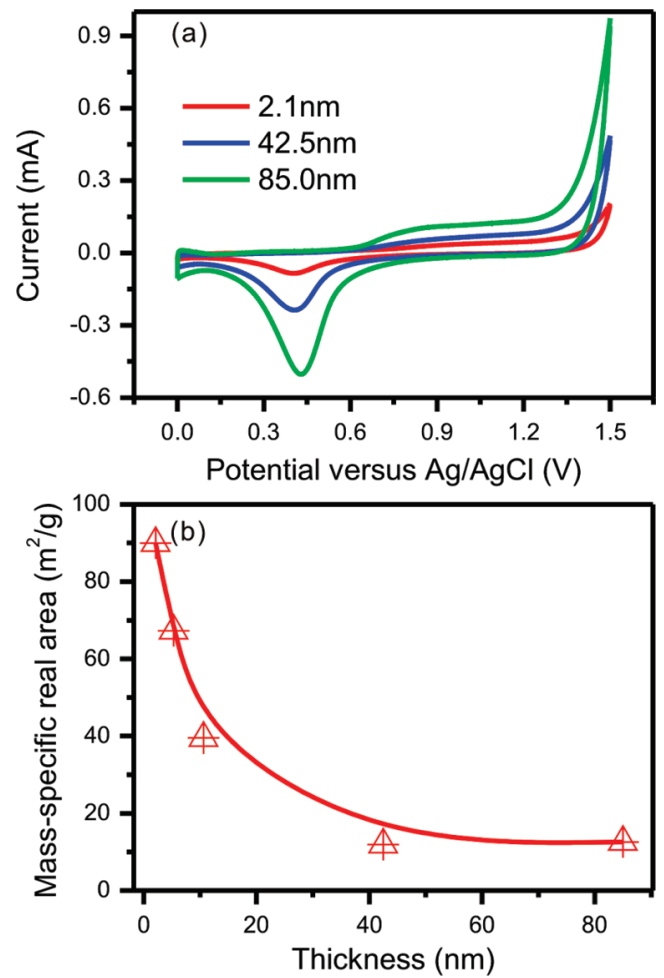

Figure 3. (a) Typical CV profiles of different thickness of $\mathrm{Pt}$ nanoclusters coated GNFs in $0.5 \mathrm{M} \mathrm{H}_{2} \mathrm{SO}_{4}$. (b) Mass-specific real area of the Pt nanoclusters coated GNFs as a function of the thickness of Pt nanoclusters.
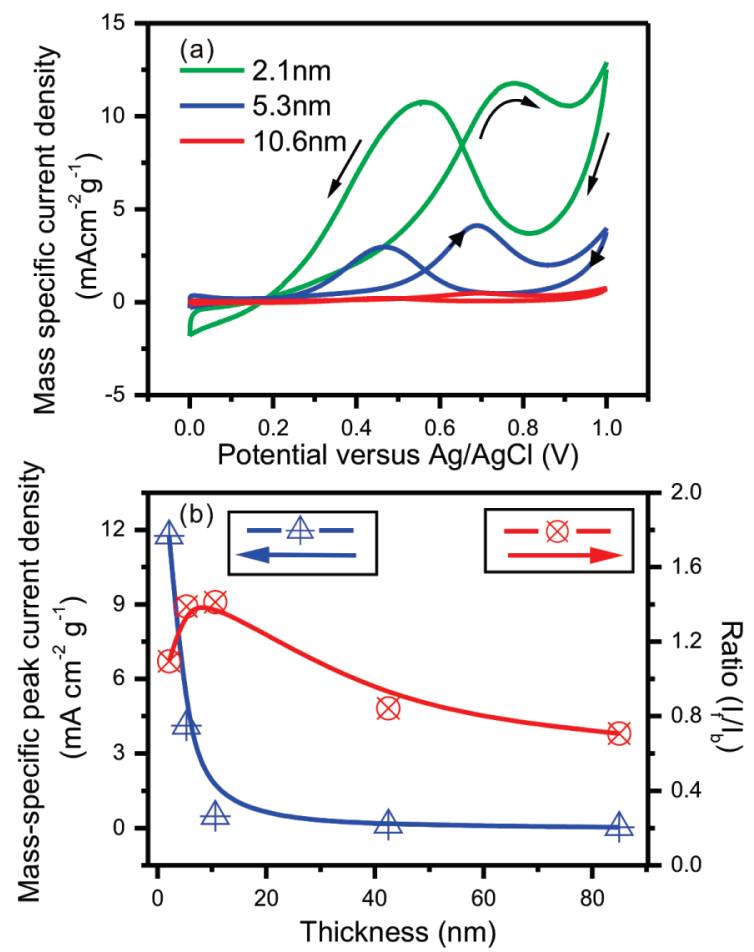

Figure 4. (a) Mass and real area double normalized $\mathrm{CV}$ profiles of $\mathrm{Pt}$ nanoclusters on GNFs for the methanol oxidation in $0.5 \mathrm{M} \mathrm{H}_{2} \mathrm{SO}_{4}+$ $1.0 \mathrm{M} \mathrm{CH}_{3} \mathrm{OH}$. (b) Mass-specific peak current density and ratio $\left(I_{\mathrm{f}} / I_{\mathrm{b}}\right)$ of the forward and backward current intensities of Pt nanoclusters coated GNFs as a function of the thickness of Pt nanoclusters.

film on the flat substrate, ${ }^{21}$ the $2.1-5.3 \mathrm{~nm}$ thick Pt nanocluster decorated GNFs only have a catalyst loading level between 4.5 and $11.3 \mu \mathrm{g} \mathrm{cm}^{-2}$, less than that of a number of highly efficient $\mathrm{Pt}-\mathrm{C}$ electrodes reported previously. ${ }^{13,22}$ Therefore, the present

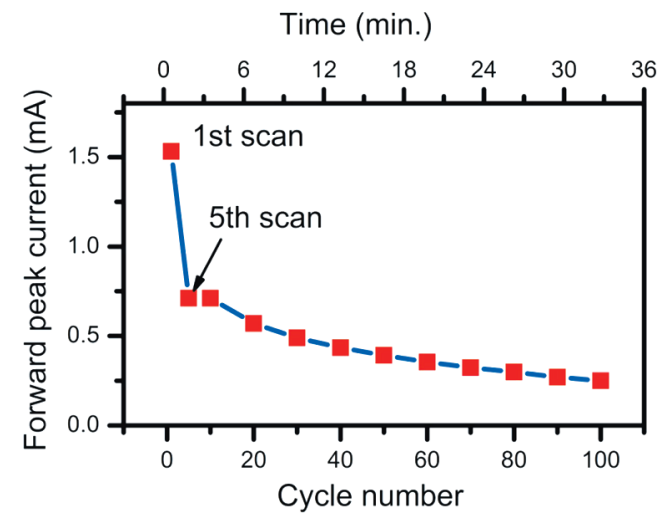

Figure 5. Forward peak current of $85 \mathrm{~nm}$ thick $\mathrm{Pt}$ nanoclusters on GNFs for the methanol oxidation in $0.5 \mathrm{M} \mathrm{H}_{2} \mathrm{SO}_{4}+1.0 \mathrm{M} \mathrm{CH}_{3} \mathrm{OH}$ as a function of both the cycle number and time.

graphene nanoflake supported Pt nanoclusters are better than the major of reported $\mathrm{Pt}-\mathrm{C}$ based electrodes. In addition, the fabrication of current $\mathrm{Pt}-\mathrm{C}$ electrode system is by combining the efficient GNF growth using CVD, which is followed by $\mathrm{Pt}$ nanocluster decoration using simple magnetron sputtering. Compared to other time-consuming, multistep methods and chemical involved, our technique is simple, highly efficient, and very facile to precisely control and to save the precious metals incorporated into devices.

The long-term stability of Pt integrated graphene electrodes has been investigated. All GNFs with different thicknesses of Pt nanoclusters have presented similar performances. Figure 5 shows the typical forward peak current of $85 \mathrm{~nm}$ thick Pt nanoclusters on GNFs as a function of the both cycle number and time for the methanol oxidation in $0.5 \mathrm{M} \mathrm{H}_{2} \mathrm{SO}_{4}+1.0 \mathrm{M}$ $\mathrm{CH}_{3} \mathrm{OH}$. It can be observed that the peak current of the methanol oxidation rapidly decreases by about $54 \%$ between the first and fifth scans and then keeps stable between the fifth and tenth scans. (For this reason, all our data used have been collected in the fifth scan.) After the tenth scan, the peak current decreases gradually with the successive scans and time. The performance is better than those of carbon nanotubes with Pt decoration on both the inner and the outer wall surfaces (about $92 \%$ loss of current after $1000 \mathrm{~s}$ running) and $\mathrm{Pt} / \mathrm{CNT}$ composites (about $77 \%$ loss of current after $600 \mathrm{~s}$ running $)^{15,17}$ and slightly poorer than that (about $72 \%$ loss of current after $1800 \mathrm{~s}$ running) of $\mathrm{Pt}$ nanocluster coated 10-20 layer graphene stacked nanosheets. ${ }^{8}$ The decay of peak currents with time has been ascribed to various intermediate species formed on the catalyst surface, which gradually accumulate to lower the electroactive area of catalysts, significantly poisoning the Pt nanocluster for the methanol oxidation.

The efficiency of electrodes in fuel cells is strongly related with the surface area and crystalline quality of the support materials as well as the dispersion and size of catalysts. The large surface area, high quality of supports, and highly dispersive catalysts with a nanoscale size would improve the electrode efficiency and decrease the loading level of precious metals used. In the present work, graphene nanoflakes and Pt nanoclusters help construct a new catalytic system for direct methane oxidation. Their excellent electrocatalytic activity could be ascribed to the following factors: (a) Uniform GNFs as a support possess a porous honeycomb-like surface structure and a larger surface area, preventing the Pt nanoclusters from coalescing and thus leading to form highly dispersed, high density, ultrasmall sized Pt nanoclusters with a high activity. In addition, this unique nanostructure different from CNTs and other carbon nanostruc- 
tures possibly enables a certain number of oriented Pt nanoclusters deposited in order along the nanoflake surface. ${ }^{23}$ These could provide a promotional effect to enhance the diffusion and removal of mainly carbon-, hydrogen-, and oxygen-containing catalyst poisons from the active Pt surface to graphene. ${ }^{24}$ The effect could become weaker with the increase of the $\mathrm{Pt}$ nanocluster thickness due to the decrease of both dispersion degree and active area of Pt nanoclusters. The details are not so clear and need to be further studied by combining theoretical calculation with extensive microstructure analysis. (b) Compared to other carbon support materials, GNFs not only have a highquality graphitized structure but also have a number of electroactive edge planes directly exposed on the surface, massively enhancing their interactions between graphene nanoflakes and Pt nanoclusters for improving the electrode efficiency. ${ }^{25,26}$ (c) The excellent nature of graphene, ${ }^{27,28}$ such as unique electronic structure, high electrical conductivity, and highly localized electronic edge state, further favors the electron transfer between the interface of graphene nanoflakes, $\mathrm{Pt}$ nanoclusters, and electrolytes.

\section{Conclusion}

GNFs have been used as an excellent support for Pt based fuel cells. Pt nanoclusters with different thickness have been deposited on GNFs and formed an advanced novel $\mathrm{Pt}-\mathrm{C}$ hybrid electrocatalytic system by the combination of simple CVD and magnetron sputtering techniques. The hybrid films are found to exhibit distinctly superior electrocatalytic activities toward methanol oxidation with an ultralow metal loading, larger $I_{\mathrm{f}} / I_{\mathrm{b}}$ ratio, and a higher mass-specific peak current compared to many $\mathrm{Pt}-\mathrm{C}$ based electrodes, thus showing substantial promise as efficient electrocatalysts in direct methanol fuel cells. The improved characteristics are associated with a network of highly intercoupled Pt nanocrystals of a monolayer thickness $(2-4 \mathrm{~nm})$ tied with the high conductivity of graphene nanoflakes. These results should be independent of the supports used for the growth of GNFs. Si wafers as the substrate of GNFs in this work enable us to fabricate microdirect methanol fuel cell by using microelectromechanical systems technology. ${ }^{29}$ This novel graphene supported Pt based nanostructure has the potential to serve as low cost and highly efficient electrodes for direct methanol fuel cells.

Acknowledgment. Authors acknowledge support from the European Union under DESYGN-IT project (STREP Project 505626-1), EPSRC Portfolio Partnership Award, EPSRC funded facility access to UK SuperSTEM in the Daresbury Laboratory.

\section{References and Notes}

(1) Novoselov, K. S.; Geim, A. K.; Morozov, S. V.; Jiang, D.; Zhang, Y.; Dubonos, S. V.; Grigorieva, I. V.; Firsov, A. A. Science 2004, 306, 666-669.

(2) Peigney, A.; Laurent, C.; Flahaut, E.; Bacsa, R. R.; Rousset, A. Carbon 2001, 39, 507-514.

(3) Chae, H. K.; Siberio-Perez, D. Y.; Kim, J.; Go, Y.; Eddaoudi, M.; Matzger, A. J.; O’Keeffe, M.; Yaghi, O. M. Nature 2004, 427, 523-527.

(4) Park, I. S.; Lee, K. S.; Jung, D. S.; Park, H. Y.; Sung, Y. E. Electrochim. Acta 2007, 52, 5599-5605.

(5) Wang, C. H.; Du, H. Y.; Tsai, Y. T.; Chen, C. P.; Huang, C. J.; Chen, L. C.; Chen, K. H.; Shih, H. C. J. Power Sources 2007, 171, 55-62.

(6) Sun, C. L.; Chen, L. C.; Su, M. C.; Hong, L. S.; Chyan, O.; Hsu, C. Y.; Chen, K. H.; Chang, T. F.; Chang, L. Chem. Mater. 2005, 17, 37493753.

(7) Ge, X. B.; Wang, R. Y.; Liu, P. P.; Ding, Y. Chem. Mater. 2007, 19, 5827-5829.

(8) Yoo, E.; Okata, T.; Akita, T.; Kohyama, M.; Nakamura, J.; Honma, I. Nano Lett. 2009, 9, 2255-2259.

(9) Xu, C.; Wang, X.; Zhu, J. W. J. Phys. Chem. C 2008, 112, 1984119845.

(10) Shang, N. G.; Papakonstantinou, P.; McMullan, M.; Chu, M.; Stamboulis, A.; Potenza, A.; Dhesi, S. S.; Marchetto, H. Adv. Funct. Mater. 2008, 18, 3506-3514.

(11) Friedrich, K. A.; Henglein, F.; Stimming, U.; Unkauf, W. Colloids Surf., A 1998, 134, 193-206.

(12) Heyd, D. V.; Harrington, D. A. J. Electroanal. Chem. 1992, 335, 19-31.

(13) Wang, H. J.; Yu, H.; Peng, F.; Lv, P. Electrochem. Commun. 2006, 8, 499-504.

(14) Li, X. G.; Hsing, I. M. Electrochim. Acta 2006, 52, 1358-1365.

(15) Wen, Z. H.; Wang, Q.; Li, J. H. Adv. Funct. Mater. 2008, 18, 959964.

(16) Seger, B.; Kamat, P. V. J. Phys. Chem. C 2009, 113, 7990-7995.

(17) Lin, Y. H.; Cui, X. L.; Yen, C.; Wai, C. M. J. Phys. Chem. B 2005, 109, 14410-14415.

(18) Guo, D. J.; Li, H. L. J. Electroanal. Chem. 2004, 573, 197-202.

(19) Mu, Y. Y.; Liang, H. P.; Hu, J. S.; Jiang, L.; Wan, L. J. J. Phys. Chem. B 2005, 109, 22212-22216.

(20) Liu, Z. L.; Ling, X. Y.; Su, X. D.; Lee, J. Y. J. Phys. Chem. B 2004, 108, 8234-8240.

(21) Gruber, D.; Ponath, N.; Muller, J.; Lindstaedt, F. J. Power Sources 2005, 150, 67-72.

(22) King, J. S.; Wittstock, A.; Biener, J.; Kucheyev, S. O.; Wang, Y. M.; Baumann, T. F.; Giri, S. K.; Hamza, A. V.; Baeumer, M.; Bent, S. F. Nano Lett. 2008, 8, 2405-2409.

(23) Du, B. C.; Tong, Y. Y. J. Phys. Chem. B 2005, 109, 17775-17780.

(24) Zeng, J. H.; Yang, J.; Lee, J. Y.; Zhou, W. J. J. Phys. Chem. B 2006, 110, 24606-24611.

(25) Okamoto, Y. Chem. Phys. Lett. 2005, 407, 354-357.

(26) Park, C.; Baker, R. T. K. J. Phys. Chem. B 1998, 102, 5168-5177.

(27) Geim, A. K.; Novoselov, K. S. Nature Mater. 2007, 6, 183-191.

(28) Kobayashi, Y.; Fukui, K.; Enoki, T.; Kusakabe, K.; Kaburagi, Y. Phys. Rev. B 2005, 71, 193406-193409.

(29) Tominaka, S.; Ohta, S.; Obata, H.; Momma, T.; Osaka, T. J. Am. Chem. Soc. 2008, 130, 10456-10457.

JP105470S 